\title{
Härtel, Reinhard, Notarielle und kirchliche Urkunden im frühen und hohen Mittelalter
}

\section{Benoît-Michel Tock}

\section{OpenEdition}

Journals

Édition électronique

URL : http://journals.openedition.org/ifha/6749

DOl : $10.4000 /$ ifha. 6749

ISSN : 2198-8943

Éditeur

IFRA - Institut franco-allemand (sciences historiques et sociales)

Référence électronique

Benoît-Michel Tock, « Härtel, Reinhard, Notarielle und kirchliche Urkunden im frühen und hohen Mittelalter », Revue de l'IFHA [En ligne], Date de recension, mis en ligne le 01 janvier 2012, consulté le 22 septembre 2020. URL : http://journals.openedition.org/ifha/6749; DOI : https://doi.org/10.4000/ifha. 6749

Ce document a été généré automatiquement le 22 septembre 2020.

(C)IFHA 


\title{
Härtel, Reinhard, Notarielle und kirchliche Urkunden im frühen und hohen Mittelalter
}

\author{
Benoît-Michel Tock
}

Ce que l'on appelait autrefois la diplomatique de l'acte privé n'a plus bénéficié d'une synthèse depuis celle, controversée, d'Alain de Boüard en 1948 et celles, vieillies, d'Otto Posse en 1887 et Oswald Redlich en 1911. C'est dire que le livre de R.H. est le bienvenu. Car c'est bien un tableau général de l'acte privé en Europe jusque vers la seconde moitié du XIIIe siècle qu'il propose, dans un livre tout à fait magistral.

La première partie, introductive, définit les concepts essentiels de la diplomatique (acte, acte privé, genres d'actes, modes de tradition ...) et fait le point à la fois sur l'histoire et le passé de la discipline.

La deuxième partie retrace l'histoire de l'acte privé. Elle se porte d'abord sur le cœur de l'Europe (« die Mitte Europas »), c'est-à-dire le monde franc, y compris l'Italie du Nord. L'auteur part du tabellionat romain pour décrire le parcours de l'acte privé jusqu'à la mise en place du notariat, en Italie septentrionale d'abord, en France et en Allemagne ensuite. Il s'intéresse au développement de l'acte ecclésiastique : notices et livres de tradition, acte scellé, charte épiscopale, acte d'officialité ... Suivent les autres types d'actes privés, notamment ceux des villes et des échevinages, avant un tour d'horizon approfondi des autres régions de l'Occident médiéval, des îles britanniques à l'Orient latin.

La troisième partie, intitulée "partie pratique ", est divisée en trois paragraphes : les lieux de conservation et les formes de tradition (l'histoire des archives ; les caractéristiques des originaux, des cartulaires ...) ; l'étude des actes privés (critique, caractères externes, caractères internes ...) ; les thèmes de recherche (« Schriftlichkeit ", actes perdus, genèse des actes, chancelleries, régions diplomatique, usage des actes, datation, faux).

On le voit, le livre de R.H. est très complet. Il est aussi d'une grande qualité, nourri par une érudition sans faille mise au service d'une diplomatique qui ne se contente pas 
d'être descriptive, mais n'a pas peur d'être interprétative. Il est bien sûr impossible de rendre compte ici de tout son contenu. On en prendra simplement quelques exemples. Dès le début de son livre, l'auteur s'interroge sur la notion d'« acte privé ». Notion contestée et floue, pour laquelle ni le critère de l'auteur (tous les actes sauf ceux émis par des souverains), qui n'est réellement opérant que pour le Haut Moyen Âge, ni celui de la force probatoire (car les actes notariaux, par exemple, en ont davantage que les notices de tradition), ni celui du contenu juridique (car le Moyen Âge ignore la distinction entre droit public et droit privé ; on aurait pu ajouter que bien des diplômes royaux ont un contenu juridique qui relève davantage du droit privé), ni enfin celui de la qualité formelle (car bien des actes délivrés par des autorités épiscopales ou urbaines sont d'apparence quelconque, alors que bien des actes notariaux sont très soignés) ne peuvent seuls suffire à donner un éclairage complet. Dès lors, et bien qu'il s'en défende un peu, R.H. se rattache à ce qui est finalement la meilleure attitude : considérer que l'acte privé, c'est toute la diplomatique, exception faite des actes des souverains, hors normes par leurs caractères propres au Haut Moyen Âge et par le poids des chancelleries souveraines à partir du XIIe siècle.

Pour les actes urbains, R.H. remonte à l'échevinage carolingien, avant de dater la naissance de l'acte d'échevinage de la fin du XIIe siècle et d'évoquer la diplomatique urbaine proprement dite (avec le sceau urbain, dont les premiers exemples sont antérieurs à l'acte d'échevins) pour terminer par le cas des «Schreinsurkunden » de Cologne et de l'amandellerie de Metz.

Un des nombreux passages stimulants est celui où R.H. étudie le concept de " région diplomatique " ("Urkundenlandschaft »). Concept à la mode, et très stimulant, mais dont R.H. rappelle qu'il n'est pas aussi neuf qu'on le croit, qu'il est complexe à étudier et que les limites d'une telle région sont difficiles à fixer.

La dernière partie de l'ouvrage comprend la reproduction, la transcription et le commentaire de 25 documents : chartes et notices, actes notariaux, notices de tradition, actes scellés, chirographe, acte d'échevinage... Un seul regret : l'absence de tout acte en langue vernaculaire.

L'ouvrage est, selon les normes de la collection, présenté de manière très didactique. Chaque paragraphe est accompagné en marge d'une brève indication de son contenu. La bibliographie comprend plusieurs centaines de titres et peut être considérée comme une œuvre en soi. L'index rerum, établi avec beaucoup de soin, est d'une très grande richesse et rendra de nombreux services aux lecteurs. C'est d'ailleurs, on l'aura compris, le cas de cet ouvrage dans son ensemble, qui marque à son tour une date dans l'histoire de la diplomatique.

Benoît-Michel Tock (université de Strasbourg) 